\title{
Effects of Salt Concentration on Storage Ability of Sauerkraut
}

\author{
K. Premakumar ${ }^{1 *}$, S. Sahana ${ }^{2}$, M. A. S. F. Sabrana ${ }^{1}$ \\ ${ }^{1}$ Department of Agricultural Chemistry, Faculty of Agriculture, Eastern University, Chenkalady 30350 Sri \\ Lanka \\ ${ }^{2}$ Department of Biosystems Technology, Faculty of Technology, Eastern University, Chenkalady 30350 Sri \\ Lanka
}

*Corresponding Authors: K. Premakumar, Department of Agricultural Chemistry, Faculty of Agriculture, Eastern University, Chenkalady 30350 Sri Lanka

\begin{abstract}
A research study was conducted, to evaluate the physicochemical properties and quality of spontaneously fermented cabbage at five $\mathrm{NaCl}$ salt concentrations: $1.0 \%, 2 \%, 3 \%, 4 \%, 5 \%$ (w/w) were used as treatments and $0 \%(w / w) ~ N a C l$ was used as control with 4 weeks of storage period. For this study, Brassica oleracea $L$. was shredded, salted and packed into glass jars and kept under anaerobic conditions for fermentation at $29^{\circ} \mathrm{C} \pm 2$ for 7 days. After initial fermentation physico-chemical analysis vz-pH, titratable acidity, total soluble solids(TSS), total sugars(TS), ascorbic acid, moisture and ash content and sensory evaluation was conducted and based on the scores, most preferred three formulations T2, T3, T4 were selected for storage study at ambient conditions for 4 weeks. The physico-chemical analysis of stored sauerkraut samples revealed an increasing trend in titratable acidity (0.21-0.7\%), TSS (18.94-110.51 mg/kg) and decreasing trend in pH (5.72-3.94), moisture (90.84-83.86\%), ash (3.51-2.94\%) and vitamin C content (0.41-0.08 mg/kg), and TS was observed increasing on week 1 and shown a decreasing trend in the later part (45.21-37.85mg/kg). The sensory assessment revealed that there was significant increase in overall acceptability for the treatments with 2-3\% salt solution in colour, aroma and taste, and all the salted treatments were observed for microbial test. At the end of the study, sauerkraut prepared with $3 \% \mathrm{NaCl}$ was preferred for desirable nutritive values up to 21 days at ambient storage.
\end{abstract}

Keywords: Brassica oleracea L, $3 \% \mathrm{NaCl}$, storage, physico-chemical analysis

\section{INTRODUCTION}

Sauerkaurt is a fermented food, which is more popular among consumers because of its health related benefits. The bio-preservation of lactic acid fermentation of vegetables is an important technology to enhance the nutritional, sensory and shelf-life properties of vegetables. Microorganisms have been used for thousands of years to grow and preserve food through the fermentation method. Traditionally, fermented vegetables and fruits are produced by considering the raw material as natural, resident micro flora. When the dominant micro flora (i.e., LAB-Lactic Acid Bacteria) is used as the starter during the fermentation process, this technique is proven to be effective. The microbial preparation of a large number of single cells or a mixture of microorganisms can be described as a starter culture. Before fermentation, the starter culture is applied to the raw material to speed up the process and to dominate a specific micro flora on the raw material to prevent further contamination of the pathogen (Holzapfel, 2014).

Oleracea brassica L. It is a significant species of vegetable crop that includes entirely cross-fertile cultivars and forms groups with broadly different morphological characteristics (Balkaya et. al., 2005). Among them Cabbage is a good source of fibre (consisting mainly of cellulose and hemicelluloses), provitamin A, Vitamin C and B9. Cabbage is mostly sold fresh or as processed product. People basically prefer fresh green cabbage, when available, to stored cabbage. Processed products include those that are treated in vinegar, or fermented such as sauerkraut or kimchi. Fresh cut or lightly prepared products include coleslaw and ready-to-eat salad mixes that hold shredded cabbage.

For several years, LA cabbage fermentation has been widely studied to produce sauerkraut. With the popularity and success of sauerkraut, fermentation of many other vegetables has emerged, such as cucumber, beets, turnips, cauliflower, celery, radishes and carrots (Roberts and Kidd, 2005). Vegetable fermentation is characterized accordingly, based on the form of raw materials in final fermented items. 
Sauerkraut, fermented cucumbers and kimchi are the most studied lactic acid fermented vegetables mainly due to their commercial importance (Paramithiotis et al., 2010).According to Kim et al. As they have more fermentable saccharides, Chinese cabbage, cabbage, tomato, carrot, and spinach have comparatively higher fermentability than other vegetables (okra and gourds) (Kim et al., 2018).Optimization of diet by incorporating fermented vegetables with promising quantities of phytochemicals of nutraceutical importance would be a very cost effective method of disease prevention, since diet induced health improvement would not carry added costs for the health sector.

\section{Materials AND Methodology}

The sauerkraut was developed with different concentrations of brine solution with a constant amount of shredded Brassica oleracea (cabbage). This study was conducted at the Food Science Laboratory of the Department of Agricultural Chemistry, Faculty of Agriculture, Eastern University, Sri Lanka

Fermentation trials

Healthy fresh and firm cabbage Brassica oleracea var. capitata heads dense with shiny, crisp, and evergreen leaves, free of cracks, bruises, and blemishes were purchased from Public Market, Batticaloa, Sri Lanka. Fermentations were carried out in glass containers, each containing $100 \mathrm{~g}$ sliced cabbage of $2 \mathrm{~mm}$ thickness. Salt was mixed with the cabbage and the mixture was pressed tightly together and covered with a plastic lid. The fermentation temperature was kept at $30^{\circ} \mathrm{C} \pm 2$ for 14 days. The $\mathrm{NaCl}$ salt was used at concentrations of $1 \%, 2 \%, 3 \%, 4 \%$, and $5 \%$ to prepare the brine solutions.

\section{Sampling}

The prepared formulations of lactic acid fermented cabbage were stored at ambient temperature (30 \pm $1{ }^{\circ} \mathrm{C}$ ) for 14 days and subjected to shelf-life evaluation. Microbiological (Salfinger and Tortorello, 2015), Physico-chemical (titratable acidity, $\mathrm{pH}$, ascorbic acid, total soluble solids, moisture ash content, total sugar content, and reducing sugar) (AOAC, 2012), and sensory (5-point hedonic scale) analyses were performed on all the formulations to determine the quality of the lactic acid fermented cabbage in a week interval during the storage period of 4 weeks.

Most preferred four formulations from sensory analysis with control subsequently stored in the refrigerator at $4 \pm 0.5^{\circ} \mathrm{C}$ for storage studies for sensory evaluation, physicochemical, and microbial analysis. Sauerkraut was developed with the following combination of different ingredients as treatments as follows.

$100 \mathrm{~g}$ shredded cabbage with no added brine solution and soaked in sterilized water was used as control. T1 100g of shredded cabbage with $1 \%$ brine solution. T2 $100 \mathrm{~g}$ of shredded cabbage with $2 \%$ brine solution. T3 $100 \mathrm{~g}$ of shredded cabbage with $3 \%$ brine solution. T4 $100 \mathrm{~g}$ of shredded cabbage with $4 \%$ brine solution.

Sensory evaluation was conducted to evaluate organoleptic characteristics of the samples using a sensory panel consisting of 20 semi-trained panelists. The colour, taste, texture, aroma, and overall acceptability were evaluated using a five - point hedonic scale.

\section{RESULTS AND DISCUSSION}

\section{Storage Studies}

\section{Tritratable Acidity (TA)}

A significant increase $(\mathrm{p}<0.05)$ in \% TA among all sauerkraut samples were observed along the storage period (Figure 1). Throughout the storage, $2.0 \%$ and $3.0 \%$ salt treatments had a slightly higher TA level than the other treatments, and the difference was significant. The slight differences in TA level may be attributed to the higher growth of LAB at the salt concentrations from 2.0 to $3.0 \%$, which may result in slightly higher amounts of lactic acid production (Zhang et al, 2016). However, by the end of this study, TA ranged between $0.35-0.70 \%$ lactic acid for all treatments, with the $2.0 \%$ and $3.0 \% \mathrm{NaCl}$ treatments having the highest $\% \mathrm{TA}(0.7 \%$ lactic acid). Therefore, salt treatments appeared to produce adequate lactic acid by providing a favourable hypertonic condition to LAB during the storage period and could be employed to produce successful sauerkraut preservation. However, for the salt treatments, after four weeks of storage \%TA observed in this study were slightly lower than the ideal TA range of $1.0-1.5 \%$ lactic acid as suggested by Hong and Park (2000). 


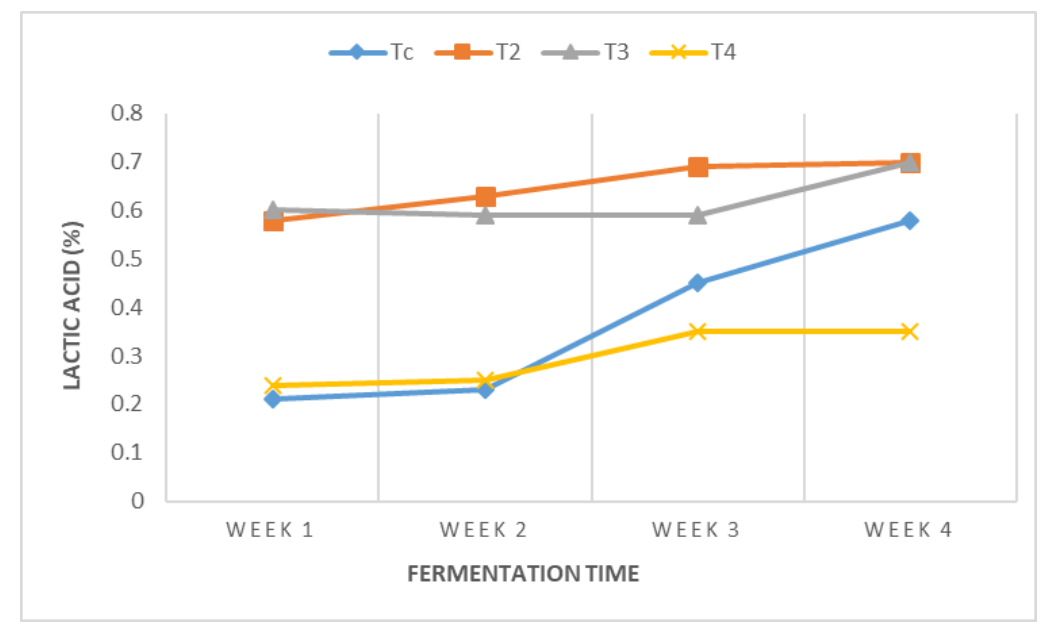

Figure1. Changes in Titratable Acidity of sauerkrauts of different treatments during storage.

$p H$

From this study (Figure 2), salt concentration appeared to have significant $(\mathrm{p}<0.05)$ effect on sauerkraut $\mathrm{pH}$ levels, the salt concentration 2-3\% significantly influence the $\mathrm{pH}$ while more than $4 \%$ doesn't. This decrease the $\mathrm{pH}$ levels most likely helped to minimize the impact of spoilage bacteria and influence the quality of the finished sauerkraut product.

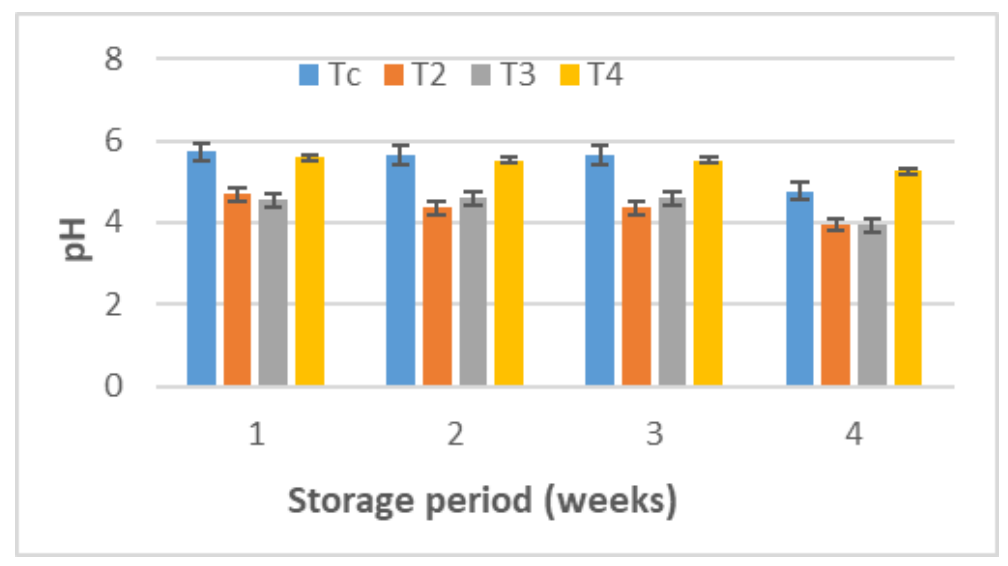

Figure2. Changes in pH of sauerkrauts of different treatments during storage.

Total soluble Solids

There were significant $(\mathrm{p}<0.05)$ increases in Total Soluble Solids among treatments and the content of Total Soluble Solids (TSS) in sauerkraut during the storage was relatively stable, and the $4 \%$ salt concentration was given, the higher the TSS value (110.51) of sauerkraut at the storage period of three weeks ( Table 1).

Table1. Change in TSS during Storage.

\begin{tabular}{|c|c|c|c|c|}
\hline Treatments & week 1 & week 2 & week 3 & week 4 \\
\hline Tc & $18.13 \pm 1.6^{\mathbf{c}}$ & $18.94 \pm 1.5^{\mathbf{c}}$ & $19.97 \pm 1.8^{\mathbf{c}}$ & $20.99 \pm 2.3^{\mathbf{c}}$ \\
\hline T2 & $79.93 \pm 0.2^{\mathbf{b}}$ & $81.15 \pm 0.5^{\mathbf{b}}$ & $82.22 \pm 0.3^{\mathbf{b}}$ & $82.23 \pm 0.3^{\mathbf{b}}$ \\
\hline T3 & $78.52 \pm 1.3^{\mathbf{b}}$ & $79.33 \pm 2.0^{\mathbf{b}}$ & $80.51 \pm 2.5^{\mathbf{b}}$ & $80.9 \pm 2.5^{\mathbf{b}}$ \\
\hline T4 & $104.11 \pm 1.1^{\mathbf{a}}$ & $106.38 \pm 0.7^{\mathrm{a}}$ & $110.51 \pm 0.2^{\mathbf{a}}$ & $110.51 \pm 0.03^{\mathbf{a}}$ \\
\hline
\end{tabular}

The values are means of replicates \pm standard error 
The means with same letters in the same column are not significantly different at $p<0.05$.

\section{Vitamin C Content}

In this study level of vitamin C (Figure 3 ) in sauerkraut during storage for all treatments was ranged between $0.08-0.41 \mathrm{~g} / \mathrm{kg}$ showing longer the storage time, lowers the vitamin $\mathrm{C}$ content applied all treatments. High solubility in water might be a reason for the decrease in the vitamin $\mathrm{C}$ content during storage as it losses even during slicing.

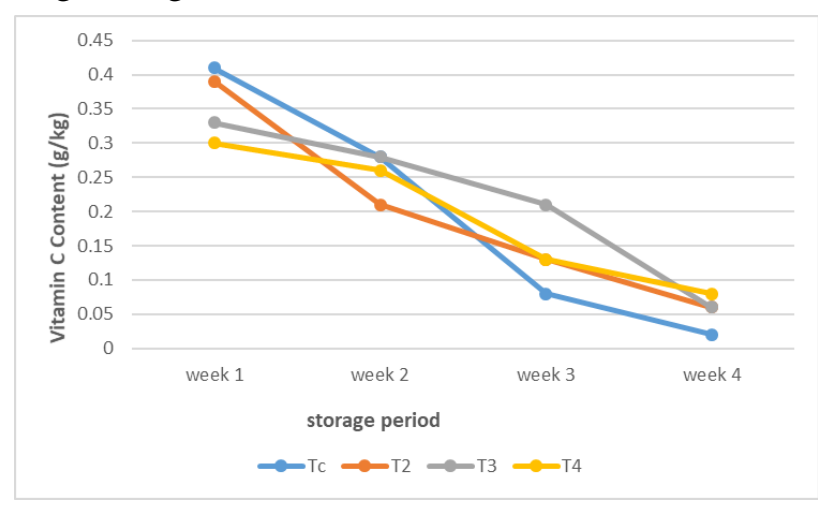

Figure3. Change in Vitamin C content of sauerkrauts of different treatments with storage period.

Total Sugar

Total sugar (Figure 4) ranged for fresh cabbage from $37.23-38.87 \mathrm{~g} / \mathrm{kg}$, and then the range significantly increased on day $7^{\text {th }}$ of storage period for all treatments. By the end of the fermentation process, the $3 \% \mathrm{NaCl}$ treatment had the lowest total sugar content and the $4 \% \mathrm{NaCl}$ brine samples had the highest concentration. However, the differences in total sugar levels among the different salt treatments were found significant $(\mathrm{p}>0.05)$ by day 28 days of storage.

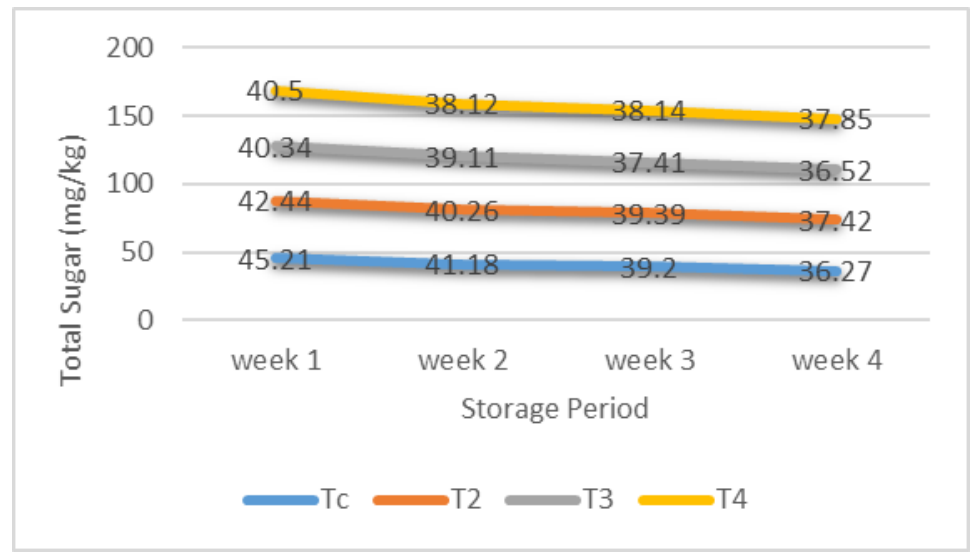

Figure4. Change in total sugar of sauerkrauts of different treatments with storage period.

\section{Ash Content and Moisture Content}

The salt content ranged from $2 \%$ to $4 \%$, suggesting that the ash content (Table 2) off sauerkraut has changed significantly by week 4 . The ash content decreases when the brine concentration is increased. Thus, several studies proved that this is due to the ion exchange phenomenon of brine solutions.

Table2. Change in Ash Content of sauerkrauts of different treatments during storage.

\begin{tabular}{|c|c|c|c|c|}
\hline Treatment & week 1 & week 2 & week 3 & week 4 \\
\hline TC & $3.51 \pm 0.01^{\mathrm{a}}$ & $3.32 \pm 0.01^{\mathrm{a}}$ & $3.29 \pm 0.02^{\mathrm{a}}$ & $2.37 \pm 0.04^{\mathrm{c}}$ \\
\hline T2 & $3.29 \pm 0.02^{\mathrm{b}}$ & $3.18 \pm 0.04^{\mathrm{b}}$ & $3.11 \pm 0.01^{\mathrm{b}}$ & $3.05 \pm 0.01^{\mathrm{a}}$ \\
\hline T3 & $3.14 \pm 0.01^{\mathrm{c}}$ & $3.16 \pm 0.04^{\mathrm{b}}$ & $3.07 \pm 0.02^{\mathrm{b}}$ & $2.99 \pm 0.02^{\mathrm{ab}}$ \\
\hline T4 & $3.26 \pm 0.01^{\mathrm{b}}$ & $3.22 \pm 0.01^{\mathrm{b}}$ & $3.09 \pm 0.02^{\mathrm{b}}$ & $2.94 \pm 0.03^{\mathrm{b}}$ \\
\hline
\end{tabular}


The values are means of replicates \pm standard error

The means with same letters in the same column are not significantly different at $p<0.05$.

In all treatments, moisture content significantly $(\mathrm{p}<0.05)$ decreased throughout the storage period reaching a minimum value of $83.86 \%$ was observed in sauerkraut with $4 \%$ brine at the end of four weeks of storage (Figure 5). The moisture content gradually reduced during storage because of osmosis and diffusion of water molecules. The moisture content was observed almost constant in control. This might be due to the absence of concentration gradient.

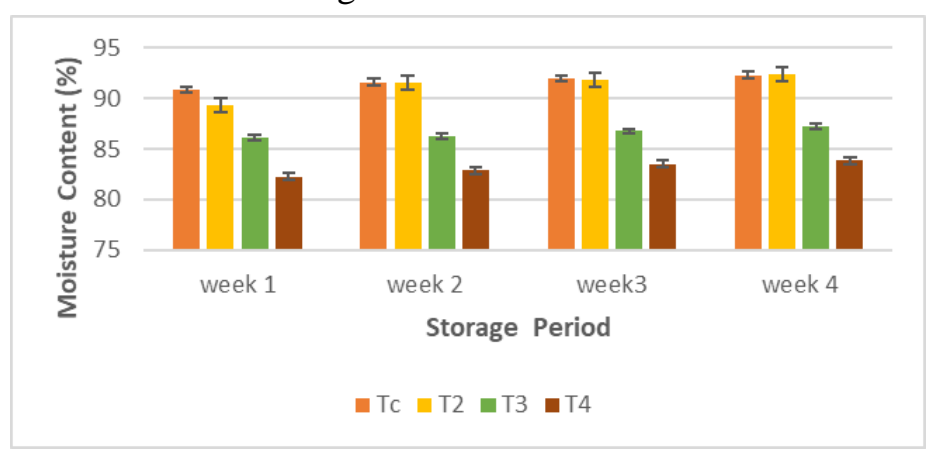

Figure5. Change in Moisture Content during Storage

\section{Sensory Evaluation}

The sensory scores with respect to colour for selected formulations were slightly increased over the period of weeks of storage. Least mean value was observed for control due to the presence of desirable green colour due to the fermentation over the time. The sauerkraut ( $3 \%$ brine) had the highest mean value score for taste and formulation Tc had the least mean value score. This might also be attributed to the oxidation of ascorbic acid into dehydroascorbic acid and degradation of tissues and increased acidity and it caused for sourness of prepared sauerkraut. There was a significant decrease in aroma of sauerkraut over the storage period of 3 weeks could be possibly due to degradation plant tissues. A decrease in texture score of Tc but, a significant increase for treatments $T_{2}$ and $T_{3}$ with scores during storage. The possible reason for decrease in texture score might be due to conversion of pectin into pectic acids and further into sugars and galacturonic acids. The mean scores for overall acceptability revealed that there were expected significant reductions in overall acceptability over the storage period of 4 weeks. Formulation $T_{2}$ had maximum mean score and formulation $\mathrm{T}_{4}$ had the least mean value score.

\section{CONCLUSION}

This research emphasizes the development and quality assessment of sauerkraut at low salt concentration. This study of quality assessment, sensory and microbiology analyses indicate that a safe and high-quality sauerkraut can be prepared at low salt concentrations.

When produced under good manufacturing and sanitation practices, sauerkraut prepared with $3 \% \mathrm{NaCl}$ was preferred for desirable nutritive values up to 21 days at ambient storage. However, microbial safety was not addressed very deeply in this study.

\section{REFERENCE}

[1] Holzapfel, W. (2014). Advances in Fermented Foods and Beverages: Improving Quality, Technologies and Health Benefits. Elsevier.

[2] Kim, H.W., Jang, J.J., Kim, N.H., Lee, N.Y., Cho, T.J., Kim, S.H., Rhee, M.S. (2018). Factors that determine the microbiological quality of ready-to-use salted napa cabbage (Brassica pekinensis): Season and distribution temperature. Food Control (Food Control). 87: 1-8.

[3] Zhang, Q., Chen, G., Shen, W., Wang, Y., Zhang, W., Chi, Y. (2016). Microbial safety and sensory quality of instant low-salt Chinese paocai. Food Control (Food Control). 59: 575-580.

[4] J. S. Roberts and D. R. Kidd, "Lactic acid fermentation of onions," Food Science and Technology, vol.38, no.2, pp. 185-190, 2005.

[5] Paramithiotis, S, Hondrodimou, O. L \& Drosinos, E. H. (2010). Development of the microbial community during spontaneous cauliflower fermentation. Food Research International, 43, 1098-1103 
[6] Hong, S. I., \& Park, W. S. (2000). Use of color indicators as an active packaging system for evaluating kimchi fermentation. Journal of Food Engineering, 46, 67-72.

[7] A.O.A.C. (2012) Official Methods of Analysis, 19th ed. Association of Official Analytical Chemists. Washington D.C. 376-384.

[8] Balkaya A, Yanmaz R, Apaydın A, Kar H (2005). Morphological characterization of the white head cabbage (Brassica oleracea var. capitata subvar. alba) populations in Turkey. New Zeal. J. Crop Hort. 33 (4): 333-341.

Citation: K. Premakumar, et.al.,, “ Effects of Salt Concentration on Storage Ability of Sauerkraut” International Journal of Research Studies in Agricultural Sciences (IJRSAS), 2021; 7(2), pp. 11-16, https://doi.org/10.20431/2454-6224.0702002

Copyright: (C) 2021 Authors. This is an open-access article distributed under the terms of the Creative Commons Attribution License, which permits unrestricted use, distribution, and reproduction in any medium, provided the original author and source are credited. 